\title{
Conservatism as a predictor of responses to humour-II. The location of sense of humour in a comprehensive attitude space
}

\author{
Ruch, Willibald ; Hehl, Franz-Josef
}

\begin{abstract}
It was attempted to locate dimensions of sense of humour in the attitude space. While previous results suggest that appreciation of jokes based on the incongruity-resolution structure is mainly a function of conservatism, the present paper examined the role of toughmindedness, as the second dimension in the attitude space. Subjects were 115 male and female students. Four conservatism questionnaires (C Scale: Wilson and Patterson, 1970; POI: Eysenck, 1976; MK: Cloetta, 1983; 16PF Q1: Schneewind, Schröder and Cattell, 1983), the 16PF scales E, G, I and M, the Allport-Vernon-Lindzey 'Study of Values' scales (Theoretical, Economic, Aesthetic, Social, Political and Religious interest), toughmindedness, capitalism, machiavellianism, disinhibition, rigidity and intolerance of ambiguity were used as marker variables in a factor analysis to identify the two major dimensions of the attitude space, conservatism and toughmindedness. An item factor analysis of 158 attitude items served as a second means to establish a frame of reference for the location of the humour scales. The results showed that funniness of jokes based on the incongruity-resolution structure was located on the conservative side, while funniness of nonsense jokes was located on the liberal side of the C-axis. Appreciation of sex as a salient content in jokes was predicted by toughmindedness. Accordingly, incongruity-resolution sex jokes were located in the toughminded/conservative quadrant, but nonsense sex jokes were located on the T-axis. All rejection scores were located on the tenderminded side. The correlation with conservatism depended on the joke's structure, e.g. rejection of incongruity-resolution jokes was located in the tender/liberal quadrant, while rejection of nonsense jokes was located in the tender/conservative quadrant. The hypotheses were tested at the level of single jokes and also at a higher order level.
\end{abstract}

DOI: https://doi.org/10.1016/0191-8869(86)90085-1

Posted at the Zurich Open Repository and Archive, University of Zurich

ZORA URL: https://doi.org/10.5167/uzh-77527

Journal Article

Originally published at:

Ruch, Willibald; Hehl, Franz-Josef (1986). Conservatism as a predictor of responses to humour-II. The location of sense of humour in a comprehensive attitude space. Personality and Individual Differences, $7(6): 861-874$.

DOI: https://doi.org/10.1016/0191-8869(86)90085-1 
This manuscript was published as:

Ruch, W. \& Hehl, F.-J. (1986). Conservatism as a predictor of responses to humour-II. The location of sense of humour in a comprehensive attitude space. Personality and Individual Differences, 7, 861-874. 
CONSERVATISM AS A PREDICTOR OF RESPONSES TO HUMOUR-II. THE LOCATION OF SENSE OF HUMOUR IN A

COMPREHENSIVE ATTITUDE SPACE. *

WILLIBALD RUCH and FRANZ-JOSEF HEHL

Department of Experimental Biological Psychology,

University of Düsseldorf,

Universitätsstraße 1 ,

D-4000 Düsseldorf,

F.R.G.

* This paper is partly based on data presented at the 5th International Congress on Humour, Cork, Ireland, 26-30 June, 1985.

Summary-It was attempted to locate dimensions of sense of humour in the attitude space. While previous results suggest that appreciation of jokes based on the incongruity-resolution structure is mainly a function of conservatism, the present paper examined the role of toughmindedness, as the second dimension in the attitude space. Subjects were 115 male and female students. Four conservatism questionnaires (C Scale: Wilson and Patterson, 1970; POI: Eysenck, 1976; MK: Cloetta, 1983; 16PF Q1: Schneewind, Schröder and Cattell, 1983), the 16PF scales E, G, I and M, the Allport-Vernon-Lindzey 'Study of Values' scales (Theoretical, Economic, Aesthetic, Social, Political and Religious interest), toughmindedness, capitalism, machiavellianism, disinhibition, rigidity and intolerance of ambiguity were used as marker variables in a factor analysis to identify the two major dimensions of the attitude space, conservatism and toughmindedness. An item factor analysis of 158 attitude items served as a second means to establish a frame of reference for the location of the humour scales. The results showed that funniness of 
jokes based on the incongruity-resolution structure was located on the conservative side, while funniness of nonsense jokes was located on the liberal side of the C-axis. Appreciation of sex as a salient content in jokes was predicted by toughmindedness. Accordingly, incongruity-resolution sex jokes were located in the toughminded/conservative quadrant, but nonsense sex jokes were located on the T-axis. All rejection scores were located on the tenderminded side. The correlation with conservatism depended on the joke's structure, e.g. rejection of incongruity-resolution jokes was located in the tender/liberal quadrant, while rejection of nonsense jokes was located in the tender/conservative quadrant. The hypotheses were tested at the level of single jokes and also at a higher order level.

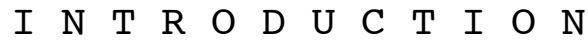

Recently we introduced the hypothesis that preference of humour based on the incongruity-resolution structure is affected by an individual's usual way of dealing with ambiguous uncertain stimuli (Ruch, 1984; Ruch and Hehl, 1983a, 1985a, 1986a). In short, conservatism as well as intolerance of ambiguity questionnaires (as measures of stimulus avoidance) correlated positively with funniness ratings of jokes based on the incongruity-resolution structure. These are jokes in which the surprising divergence between the joke body and the unexpected punchline can be made meaningful by finding a 'cognitive rule' (Suls, 1972) which makes the joke ending predictable by the joke body. Suls postulated that the surprise experienced creates a need to make joke body and joke ending congruent. He predicted positive relations between degree of incongruity, amount of surprise experienced, the need to solve the problem, and appreciation of the joke. Our hypothesis was that there are a priori differences between Ss with regard to their need to avoid uncertain (in the sense of information theory, i.e. complex, ambiguous, incongruent, novel) stimuli and the preference for stable and predictable ones. These individual differences can be predicted by conservatism or intolerance of ambiguity scales. Our hypothesis suggests that the general tendency to avoid uncertain stimuli will interact with the need to overcome the surprise induced by the punchline. Conservatives (as well as ambiguity-intolerants) experience the resolution of the incongruity (reduction of uncertainty) as more pleasant than their opposites. On the other hand, they will reject jokes which do not allow reduction of uncertainty. This is the case with absurd nonsense jokes which contain incongruities that cannot be resolved, or in which the resolution adds new incongruities. Both types of jokes, INC-RES jokes and nonsense jokes, were established by several factor analytic investigations (Ruch, 1981, 1984). Jokes which make up these factors were different in content but homogeneous with regard to their structure. Additionally, a third factor was extracted which contained jokes of both structures but one common salient content, sexuality. This factor contains two clusters, INC-RES sex jokes and NON sex jokes, which also have a loading on the first or the second factor respectively, depending on their structure.

Previous results suggested that the German version of the Wilson and Patterson (1970) conservatism scale (C Scale) is positively associated with funniness of INC-RES jokes, moderately with funniness of sex jokes, and rejection of NON jokes and slightly negatively with funniness of NON jokes (Ruch, 1984; Ruch and Hehl, 1983a, 1985b, 1986a). On the other hand, the conservatism scale of Eysenck (1976) and the Intolerance of Ambiguity questionnaire were correlated with funniness of sex jokes and only moderately 
with funniness of INC-RES jokes. We argued that the differences might be explained by the second dimension in attitudes, toughmindedness. There is some evidence that sex jokes are preferred by toughminded Ss (Terry and Ertel, 1974; Hehl and Ruch, 1985; Ruch and Hehl, 1985b, 1986b). Our model is that conservatives generally prefer humour based on the incongruityresolution structure (and reject nonsense humour), but among conservatives, tenderminded Ss prefer the first factor containing INC-RES jokes of different contents and toughminded Ss prefer sex jokes.

Recently we showed that value orientation affected preference of INC-RES sex jokes, but not preference of NON sex jokes (Ruch and Hehl, 1986b). Ss scoring high on the 'Economic' and 'Political' scales of the Allport-VernonLindzey (1960) 'Study of Values' and low on the 'Aesthetic' and 'Social' scales had high funniness scores on the sex joke factor. Ss with high 'Social', 'Religious', and 'Aesthetic' scores and low 'Economic' and 'Political' interests rejected sex jokes. Eysenck (1954) demonstrated that these four scales are located along the toughmindedness-conservatism diagonal in the attitude space; with economic and political (interest in power) in the toughminded-conservative quadrant and social and aesthetic in the tenderminded-radical quadrant. This location of the significant predictors of sex jokes underline the relevance of toughmindedness.

Unfortunately, the three dimensions (radicalism, capitalism and toughmindedness) of the 'Public Opinion Inventory' were highly interrelated and thus were no good frame of reference for locating the humour scales in the attitude space. In particular, the correlation between toughmindedness and conservatism was too highly negative. Additionally, the items of the German version of the $\mathrm{C}$ Scale are only scorable for conservatism but not for Wilson's 'realism' (toughmindedness) factor. In order to give an exact location of the humour scales in the attitude space, an item factor analysis of several conservatism scales will be carried out. Then the humour scales will be correlated with the factor analytically derived axes of the attitude space. The hypothesis introduced above will be tested more stringently. Accordingly, we can see whether or not the tough-tender mindedness dimension is related to the preference for salient contents of jokes. It seems to be reasonable to separate INC-RES sex jokes, NON sex jokes, and pure sex jokes in this study, in order to evaluate whether the toughmindedness hypothesis is generally valid for sex jokes (i.e. irrespective of the jokes's structure) or not.

Although toughmindedness is an attitude dimension, it bears a relation to temperamental variables. Eysenck (1954) considered toughmindedness as

...'the projection on to the social attitudes field of a set of personality variables' (p. 170).

More recently (Eysenck and Wilson, 1978), Psychoticism (P) has been seen as the more relevant variable; toughmindedness is now regarded as synonymous with P (Eysenck and Eysenck, 1985). Therefore the weak German version of the toughmindedness scale can be probably supported by other scales which are usually correlated with toughmindedness. Thus, a second approach in this investigation will be building up an attitude space with the help of factor analysis using marker variables for conservatism and toughmindedness. Correlations between the factor scores and the humour scales will again be calculated and the resulting correlation coefficients will help in locating the humour scales in a second independent way. A comparison of the results of 
these two alternative approaches will show whether they lead to similar conclusions or not.

The hypotheses will be tested in three different ways: First, the factor scores of the Conservatism and Toughmindedness axes will be correlated with the humour scales. Second, the Funniness and Rejection ratings of single jokes will be correlated separately with the conservatism and toughmindedness factors, in order to examine whether the results are valid for each member of the categories or not. Third, we will examine whether there is a higher order structure in the results found for the single jokes. The correlations with the criterion variables should be higher for jokes which are more typical representatives of the categories than for those which are less representative. Tucker's PHI will be used to examine the strength of this relationship.

The attitude space

Factor analyses of the Wilson and Patterson C Scale usually lead to a strong general conservatism/liberalism factor and a minor 'realism/idealism' factor, which is independent of the first one (Wilson, 1985). Eysenck's (1976) model consists of three factors: radicalism/conservatism, toughmindedness/tendermindedness (in his former model there have only been these two factors) and economic capitalism/socialism. Eysenck and Wilson (1978) claim, that the first two factors of the two models are identical (or can be made identical by rotating the $\mathrm{C}$ Scale slightly to Eysenck's $\mathrm{R}$ factor in order to reduce the loading of the $\mathrm{C}$ Scale on toughmindedness). For this reason, the two factors will be used as a frame of reference for the location of sense of humour.

M E T

Subjects and material

Subjects were 121 ( 61 male) students of the University of Duisseldorf coming from different faculties with the exception of psychology. They were recruited by means of advertisements and were paid for their services. The range in age was 18 - $32 \mathrm{yr}$; with a mean of $22.6 \mathrm{yr}$. The testing session lasted $4 \mathrm{hr}$; including breaks. Six Ss had incomplete sets of data leaving 115 Ss for the further analysis. Among other questionnaires, they answered four conservatism questionnaires:

C Scale: Wilson and Patterson (German version by Schneider and Minkmar, 1972). Forty items in a 'catchphrase' format usually form a potent general (conservatism) factor and a minor orthogonal 'idealism-realism' factor. Answer format is trichotomous.

POI: Public Opinion Inventory (Eysenck, 1976). Eighty-eight items are rated on a 5-point rating scale according to degree of agreement/disagreement. Factor analysis revealed three slightly correlated components: RadicalismConservatism (POIR), Capitalism-Socialism (POIC), and ToughmindednessTendermindedness (POIT).

MK: Cloetta (1983). The questionnaire contains 18 conservatism (MKC) and 18 machiavellianism (MACH) items. Ss mark for each statement the degree to which they think it is true or false on a 6-point scale.

16PF Q1: Schneewind et al. (1983). The Q1 subscale (16PF Q1) of the German version of Cattell's $16 \mathrm{PF}$ is in fact a radicalism scale with conservatives 
scoring low on it. In order to get comparable results, we inverted the scores.

Additionally, rigidity (RIG), intolerance (INT-A) of ambiguity (Brengelmann and Brengelmann, $1960 \mathrm{a}, \mathrm{b}$ ), and the Allport-Vernon-Lindzey 'Study of Values' (Roth, 1972) were administered. The latter provides scores for a S's 'theoretical', 'economic', 'aesthetical', 'social', 'political' and 'religious' interests. These scales can be used as markers for the toughmindedness factor (Eysenck, 1954). Other relevant subtests of the 16PF were also used, namely Dominance (16PF E), Superego Strength (16PF G), Tendermindedness (16PF I), and Autia (16PF M). Finally, the Disinhibition (DIS) subscale of the SSS-IV (Zuckerman, 1979) was used as a marker for toughmindedness.

Both forms (3WD-A; 3WD-B) of the humour tests were used and combined for ease of presentation and to enhance reliability. In both forms 10 incongruity-resolution jokes (INC-RES), 10 nonsense jokes (NON), and 10 sex jokes (SEX) are presented in random order and have to be rated on two unipolar 7-point rating scales according to the criteria, funniness (f) and rejection $(r)$. Thus, six scores can be obtained: INC-RESf, NONf, SEXf, INCRESr, NONr, and SEXr. Here rejection of a joke is used to mean that a person reacts to a joke with a negative emotion; e.g. with indignation, embarrassment or boredom.

R E S U L T S

Factor analysis of maeker variables for conservatism and toughmindedness

A principal component analysis of these 20 marker variables ( 4 conservatism scales, DIS, 16PF scales E, G, I and M, RIG, INT-A, MACH, POIT, POIC and the six value scales) was carried out. The first two factors (which explained $41 \%$ of the variance) were extracted, although eigenvalues in excess of unity were found for 6 factors and the scree test, too, suggested the retention of this number of factors. Factors 3 to 6 were mainly made up by the additional variables. The principal components were clearly interpretable as 'conservatism vs liberalism/radicalism' and 'toughmindedness/realism vs 'tendermindedness/idealism', but a slight rotation (190) would have made the position more exact. The six humour scores, sex and age were projected into the two-dimensional space by using their correlation coefficients with the factor scores as coordinates (see Fig. 1 ).

Insert figure 1 about here

The conservatism axis was mainly loaded by the four conservatism scales, rigidity (RIG), intolerance of ambiguity (INT-A), and the 16 PF scales Superego Strength (16PF G) and Praxernia (16PF M). As predicted, theoretical, political, and economic value had positive loadings, and religious and social value had negative loadings on the toughmindedness factor. Machiavellianism $(\mathrm{MACH})$, dominance (16PF E), disinhibition (DIS), and the Toughmindedness (POIT)-scale marked the 'tough' side of this axis and Tendermindedness (16PF I) and Superego Strength (16PF G) marked the 'tender' side. The POIT and 16PF I scales had a 'liberal bias'; beside their expected tough respectively tendermindedness loadings both of them loaded negatively on the conservatism 
factor. They were not positioned on opposite points in the attitude space; also their intercorrelation $(r=-0.01$, NS) showed that a suppressor variable might exist. There were some irregularities in the loadings which could be deleted completely by a slight rotation of the whole coordinate system to the right for about 190 (new position of the axes at the points $C^{\prime}$ and $T^{\prime}$ ). Thus, now theoretical interests and DIS had their expected second loading on the liberal side and religious value loaded on the conservative side; MACH lost its too high conservatism loading, being imaginative (16PF M) and interested in aesthetics became a characteristic of the tenderminded, and the factor loading of INT-A on toughmindedness was increased. Also Eysenck's conservatism scale fell on the tough side of the coordinate system by this rotation. Now, both the $\mathrm{C}$ Scale as well as POIR loaded approx 0.80 on the $\mathrm{C}$ ' axis, but the former loaded -0.28 on the $T^{\prime}$ axis and the latter 0.28 . The new position of the axes exactly replicated the findings of E.I. George (cited in Eysenck, 1954) regarding the location of the Allport-Vernon-Lindzey value scales.

\section{ITEM FACTOR ANALYSIS}

The second way to establish a comprehensive attitude space was to calculate a factor analysis at the item level. Therefore, 158 items (12 items of $16 \mathrm{PF}$ Q1, 40 items of the C Scale, 18 items of the MK and all 88 POI items) were intercorrelated and subjected to a principal-component analysis. Although eigenvalues in excess of unity were found for more than 40 factors, the scree test suggested the retention of either 3 or 7 factors. Three factors were extracted and principal components scores were calculated. In this three-dimensional system the first two axes were clearly identifiable as conservatism and toughmindedness. The capitalism factor also emerged but had to be rotated towards the first two axes and is not independent of them.

The factor scores were correlated with the 20 marker variables of the first analysis and the six humour scores. Although the 'loadings' were smaller, nearly the same configuration appeared as in the first analysis. In order to make the locations perfect, the coordinate system had to be rotated to the right by about 180 (to the position $\mathrm{C}^{\prime \prime}$ and $\mathrm{T}^{\prime \prime}$ ). After the rotation again the MKC and 16PF Q1 conservatism scales and RIG and 16PF M were the best markers of the conservatism factor. The C Scale (0.81) and POIR (0.72) had the highest correlations with the C''-axis, but the former correlated 0.32 with the T''-axis and the latter 0.31 .

The factors of the two approaches correlated highly ( $r C^{\prime} ; C^{\prime} '=0.89$, $\left.r T^{\prime} ; T^{\prime} '=0.78\right)$ and the cross factor correlations were zero $\left(r C^{\prime} ; T^{\prime}{ }^{\prime}=0.00\right.$, $\left.r C^{\prime}{ }^{\prime} T^{\prime}=-0.01, N S\right) ; i . e$. they served as a comparable frame of reference for the location of the sense of humour scales within the attitude space. The factor loadings of the 20 marker variables of the first analysis and the correlations of these variables with the $C^{\prime \prime}$ and $T^{\prime \prime}$ axes were examined for their correspondence. We again used Kaiser's method to relate the two systems. The cosines between the corresponding axes (0.999) showed that only a 10 rotation would be necessary to obtain a maximum correspondence in the position of the axes. Tucker's Phi-Coefficients for the two factors before rotation were 0.99 and 0.95 . We also calculated the coefficients for the variables and it turned out that the positions of the variables were nearly 
identical (range $0.97-1.00$, mean of the cosines $=0.99$ ) with the exception of POIC (0.88) and aesthetic value (0.94). In the second analysis, the capitalism scale had a toughmindedness loading.

Locations of the humour scales in the two dimensional space

What was the position of the humour scores with regard to the new axes? Figure 1 shows that INC-RESf was located directly on the C'-axis while SEXf was located in the conservative/toughminded quadrant; i.e. it was correlated positively with both axes $C^{\prime}$ and $T^{\prime}$. NONf was in the tough/liberal quadrant with generally low coordinates. All rejection scales could be found at the tenderminded side of $T^{\prime}$. In detail, INC-RES and SEX jokes were located in the tender/liberal quadrant and NON jokes in the tender/conservative quadrant. The results showed that both, INC-RES jokes and sex jokes were preferred by conservatives, but the latter were especially appreciated by tough conservatives. As might be expected, male sex correlated significantly with $T^{\prime}(r=0.24, P<0.05)$ but not with $C^{\prime}(r=0.11$, NS $)$. There were no significant correlations between (male) sex and $\operatorname{SEXf}(r=0.18)$ and $\operatorname{SEXr}(r=-0.15)$. Therefore, the relationship between $T^{\prime}$ and sex jokes cannot be attributed to sex differences.

The exact correlations of the humour scores with the $\mathrm{C}^{\prime} / \mathrm{C}^{\prime}$ ' and $\mathrm{T}^{\prime} / \mathrm{T}^{\prime}$ ' axes are presented in Table 1. It can be seen, that the humour scores correlated with the $C^{\prime \prime}$ and $T^{\prime}$ ' axes even higher than with $C^{\prime}$ and $T^{\prime}$ '. For example, $C^{\prime \prime}$ and T'' together correlated 0.56 with SEXf and -0.49 with SEXr (The corresponding values for $C^{\prime}$ and $T^{\prime}$ were 0.54 and -0.39 ). Taking into account that the humour scores have internal consistencies of 0.91 (SEXf) and $0.95(\mathrm{SEXr})$, the correlations with the true scores were 0.59 and 0.50 , respectively.

Additionally, we separated the sex jokes into those with a relatively high second loading on the INC-RES factor ( 6 jokes), the NON factor ( 3 jokes), and those which were relatively 'pure' (11 jokes; most of them were based on the INC-RES structure); their Funniness and Rejection total scores were derived and correlated with the factor scores (see Table 1).

Insert Table 1 about here

In both analyses, Funniness of sex jokes based on the nonsense structure was not correlated with the conservatism axis. The correlation coefficients for Funniness of INC-RES sex jokes and Funniness of pure sex jokes were higher than for all sex jokes combined. Generally speaking, toughmindedness was associated positively with all three groups of sex jokes but only those sex jokes that were based on the incongruity-resolution structure were also correlated with conservatism. The INC-RES sex jokes generally have a higher correlation with $C^{\prime}$ than with $T^{\prime}$. The correlations of the pure sex jokes with $\mathrm{C}^{\prime}$ and with $\mathrm{T}^{\prime}$ were about equal on the average and NON sex jokes did not correlate with $\mathrm{C}^{\prime}$ but with $\mathrm{T}^{\prime}$.

The toughmindedness axes were correlated highly negatively with all Rejection scores (especially in the second analysis). Additionally, Rejection 
of INC-RES sex jokes and of pure sex jokes correlated negatively and Rejection of NON sex jokes correlated positively with the C-axes. The opposite signs of the correlations with $C^{\prime}$ reflect the importance of the structure component of jokes even in the Rejection scores. Each of these jokes was rejected by tenderminded Ss because of the common content of these jokes, sexuality. Additionally, sex jokes were rejected by (tender) conservative

Ss if the jokes were based on the nonsense structure and rejected by (tender) liberal Ss if the jokes were based on the incongruity-resolution structure.

Correlations between the Funniness and Rejection ratings of single jokes and the rotated $\mathrm{T}^{\prime}$ and $\mathrm{C}^{\prime}$ axes

The Funniness and Rejection scores of the 60 jokes (of Form A and B) were correlated separately with the (rotated) $C^{\prime}$ and $T^{\prime}$ factor scores, in order to see whether the results found for the whole joke category also emerged for each member of the category (see Tables 2 and 3 ). The first three of the sex jokes (columns 5 and 6 ) are INC-RES sex jokes, followed by 3 NON sex jokes and 11 pure sex jokes.

Insert Tables 2 and 3 about here

Generally it turned out, that all of the 37 jokes based on the INC-RES structure correlated positively with the C axis and nearly all (81\%) of these correlations were significant. The C'-axis correlated negatively with 17 of the 23 jokes based on the NON structure (four of them were significant) these jokes were judged as funny by liberals. Three INC-RES jokes also correlated positively with the T' axis, one of these had a slight sexual connotation, one was very aggressive and the most significant one was a 'put down' joke. All SEX jokes correlated positively with the T'-axis and 15 of these were significant.

The results for the Rejection scores reveal positive as well as negative correlations for the $C^{\prime}$ axis of which 16 were significant at least at the 5\% level. All correlations with the T' axis except four (one INC-RES and three NON jokes) were negative and 25 were significant. The separation of the sex jokes into the three groups showed that the correlations with the $C^{\prime}$ axis were generally positive for Rejection of NON sex jokes and negative for Rejection of INC-RES sex jokes and of pure sex jokes.

The analyses employing the $C^{\prime}$ ' and $T^{\prime}$ ' axes will not be presented here because generally the same results appeared; most of the correlations were slightly increased and some additional ones were significant. For example, now the Rejection scores of all sex jokes correlated with T'' (11 at $0.1 \%$, 7 at $1 \%$ and 2 at $5 \%$ ) and they were much higher (range -0.21 to -0.51) than before. 
Comparison of joke factor structure and the profile of the joke's correlations with $\mathrm{C}^{\prime} / \mathrm{C}^{\prime} '$ and $\mathrm{T}$ '/T''

In step three we examined whether there was a higher order relationship in the results found. The correspondence between the profiles of the

correlations of the jokes with conservatism and toughmindedness and the shape of the loadings of the jokes on the INC-RES and the sex joke factor were compared using Tucker's PHI coefficient. The hypotheses were:

(a) the higher a joke's correlation with C', the more typical this joke is for the incongruity-resolution factor (i.e. the higher is the loading on this factor). Jokes that are not based on this structure are also not correlated with $\mathrm{C}^{\prime}$.

(b) the higher a joke's correlation with $\mathrm{T}^{\prime}$, the more typical this joke is for the sex joke factor (i.e. the higher is the loading on this factor). Jokes with other non-salient contents are also not correlated with $T^{\prime}$.

First we had to calculate a principal component analysis of the funniness ratings of the 60 jokes, extract the first three factors and rotate them with the varimax routine. The factors appeared very clearly; in order to establish the best position, we rotated the INC-RES and SEX factor a few degrees orthogonally. Kaiser's et al. (1971) method of relating factor structure showed that this was about the best position of correspondence of the correlation pattern and loadings.

Tucker's PHI coefficient was used to examine the strength of the relationship of the corresponding profiles of the factor loadings in the INCRES and sex joke factor and the correlations of the jokes with the factor scores of the $C^{\prime}$ and $T^{\prime}$ axes (the results for $C^{\prime \prime}$ and $T^{\prime}$ ' will be given in parentheses). The cosines between the pattern of the jokes correlation with $C^{\prime}$ and the loadings in the INC-RES factor was $0.81(0.84)$; the coefficient relating the $T^{\prime}$ correlations and the loadings in the sex joke factor was 0.87 $(0.86)$. In other words, the higher a joke was correlated with conservatism, the more typical this joke was for the INC-RES factor; the higher a joke was correlated with toughmindedness the more typical this joke was for the sex joke factor. The more conservatives relative to liberals appreciate a joke, the more typical this joke was for the INC-RES joke factor; the more tough relative to tender Ss appreciate a joke, the more typical this joke was for the SEX joke factor. The coefficients across the profiles were much lower (PHIC'; SEX=0.70/0.69, PHIT';INC-RES=0.53/0.47). Thus, the hypotheses can be regarded as confirmed in both analyses.

Since the hypothesis excluded the NON jokes, the same coefficients were calculated for INC-RES jokes and sex jokes combined and also separated. The coefficients for the comparison of the C-axes and INC-RES then were much higher than before; 0.95/0.96 for INC-RES jokes, 0.93/0.94 for sex jokes and $0.91 / 0.92$ for both of them. The coefficients for the comparison of $T^{\prime}$ and SEX were high, too; $0.77 / 0.70$ for INC-RES jokes, $0.98 / 0.97$ for sex jokes and $0.94 / 0.93$ for the combined analysis. Analysing NON jokes, we found coefficients of $0.05 / 0.18$ and $0.12 / 0.14$, respectively. 
The results suggest, that even among the pure INC-RES jokes toughmindedness has some relevance. The variation in the loadings on the sex joke factor that exists for INC-RES jokes (these loadings were between -0.25 and 0.32 ) can be explained by the size (and the sign) of their correlations with the $T^{\prime}$ axis $(-0.10$ and 0.27$)$. The higher this (positive) loading on the sex factor, the higher were the joke's (positive) correlations with T'. Jokes with a negative correlation with $\mathrm{T}^{\prime}$ also had a negative loading on the sex joke factor. We compared the exact position of a joke in the two spaces for each joke separately. The resulting PHI-coefficients (cosines between the locations of a joke in the two spaces) were between $0.89 / 0.94$ and $1.00 / 1.00$ (with the exception of two outliers each; 0.53/0.82 and 0.84/0.90). The average value of the coefficients was 0.94/0.97. If we hypothesize that the jokes of the first factor were characterized by their common (incongruityresolution) structure (irrespective of the joke's content) and the third factor was a content (sex) factor, we can conclude that toughmindedness can predict appreciation of other contents than sex, also. Toughmindedness accounted for the differences in the content of the jokes of Factor 1 , too. The themes of these jokes were very heterogeneous. Dividing the jokes into two groups according to the sign of their loadings on the sex factor and the correlations with toughmindedness, it can easily be seen that jokes of the group with the positive sign have a more salient ('tough') content

(aggressive, slightly sexual, superiority) whereas the jokes of the 'negative' group were really non-tendentious ('tender'). Unfortunately the variance in the loadings was not very large and the number of jokes was restricted, therefore this interpretation is done only tentative.

The results for the sex jokes were similar; the existing differences in the factor loadings of the jokes in the INC-RES factor $(0.0-0.62)$ and the sex factor $(0.16-0.68)$ could be accounted for by conservatism (range of the correlations -0.10 to 0.53$)$ and toughmindedness $(0.08$ to 0.35$)$, respectively. The structural basis of the sex jokes could be explained by conservatism and the salience of the content was predicted by toughmindedness. Although all of them were sex jokes, the themes were more or less salient; in some jokes the libidinal content was 'disguised', other jokes were very frivolous.

Toughmindedness seems to be able to account for these subtle differences in saliency of the (sexual) content. In order to test the differences in the locations of the jokes in the two spaces, we computed PHI-coefficients for each single sex joke. There was the same outlier in both analyses $(0.03 /-$ $0.62)$, a 'pure' sex joke with a generally low communality in this sample. The cosines of the other jokes were between $0.85 / 0.84$ and $1.00 / 1.00$ $($ mean $=0.92 / 0.98)$.

The relationship between the loadings of the 40 jokes on the incongruityresolution factor (abscissa) and their correlation with the $C^{\prime}$ axis (ordinate) are presented in Fig. 2 .

Insert figure 2 about here

The shape of the distribution of all jokes of Fig. 2 combined does not indicate a strong relationship. But looking at the groups of jokes separately one can see, that strong relationships exist within each group; which do not 
overlap because of their different loadings on the INC-RES factor. INC-RES jokes ( ) are very homogeneous; they have the highest loadings on the abscissa. The pure sex jokes ( ) approximately lie on a single line indicating a clear relationship. Because these jokes also have a big proportion of content variance (which contributes to the total variance), the relative contribution of the structure variance is smaller; i.e. they are on the left of the INC-RES jokes. The mixture of both, INC-RES sex jokes ( ) lies between the pure sex jokes and the INC-RES jokes indicating that there are continuous changes between these groups. If the effects of content are eliminated in these jokes (i.e. the joke's loading on the sex joke factor is partialled out), their INC-RES loadings and their correlations with $C$ increase and are comparable with the coefficients of the 'pure' INC-RES jokes. Figure 1 shows that only one of the three NON sex jokes ( ) is located on the conservative side but this joke also has a loading on the INCRES factor. The 'pure' NON jokes (which are not presented here) are clearly separated from the other groups; they lie around zero.

The relationship between the loadings of the 40 jokes on the sex factor (abscissa) and their correlation with the $T^{\prime}$ axis (ordinate) are presented in Fig. 3 .

Insert figure 3 about here

Pure sex jokes have the highest loadings on the sex factor and also the highest correlations with T'. INC-RES jokes (in which structural and content properties contribute to the funniness judgement) have lower loadings on the sex factor and lower correlations with the $T$ ' axis. Fig. 3 shows that among INC-RES jokes also there is a relationship between the two profiles. The three NON sex jokes are mixed up with the others. Only among the NoN jokes (which are not presented here) there is no relationship; they were randomly distributed around zero.

Comparison of joke correlation pattern with the $\mathrm{C}$ and $\mathrm{T}$ axes of both analyses.

The question next considered was, to what extent the jokes' correlations with the two $C$ axes $\left(C^{\prime}, C^{\prime}{ }^{\prime}\right)$ and the two $T$ axes $\left(T^{\prime}, T^{\prime}{ }^{\prime}\right)$ were comparable. The PHI coefficients showed that the patterns were very similar (between 0.94 and 0.99 for INC-RES and SEX jokes combined). The comparison of C'C'' for funniness of INC-RES jokes was 0.99 (rejection 0.97 ), the resulting coefficients for the comparison of $T^{\prime} T^{\prime}$ ' using sex jokes were 0.98 for funniness and 0.99 for rejection.

\section{I S C U S S I O N}

The aim of the present study was to locate dimensions of sense of humour in the attitude space. Previous results suggested that (a) the appreciation of jokes based on the incongruity-resolution structure is mainly a function of an individual's degree of conservatism and (b) toughmindedness predicts whether sex jokes or INC-RES jokes are preferred. Therefore, a factor space 
(with the axes conservatism and toughmindedness) was needed in order to get a frame of reference for the location of the humour scales. Both approaches, the analysis of marker variables as well as the analysis at the item level, brought comparable results. Funniness of INC-RES jokes can be located at (or somewhat above) the conservatism axis. The coefficients of this study (0.41, $0.46)$ are comparable with the correlations found in previous samples $(0.48$, 0.46 ; Ruch, 1984). Furthermore, this result could be demonstrated for nearly all of the jokes of this category. The higher-order relationship found in previous studies was also replicated; the sizes of the PHI-coefficients, too, were comparable. The hypothesis also obtained support from those sex jokes that were based on the INC-RES structure. Their loading on the structure factor (PHI=0.93/0.94) clearly seemed to be a function of the joke's correlation with conservatism. It is remarkable that a strong structure component can be separated even from jokes usually characterized as 'tendentious' .

Although INC-RESf was not significantly related to toughmindedness, neither positively nor negatively, Funniness of single INC-RES jokes was. The size and the sign of these correlations with toughmindedness corresponded to the joke's loading on the sex factor. Thus, toughmindedness probably has an influence on appreciation of the non-salient contents of Factor 1. Thus, generally one can say that jokes which are based on the incongruityresolution structure (irrespective of the content, i.e. including sex jokes) are considered funny by conservative Ss. In both analyses nonsense jokes were judged as funny by liberal ss but the size of the correlations showed that most of the variance of INC-RESf was outside the attitude space. Also in other studies (Ruch, 1984) the typical correlation was about -0.20 ; the significance depended on the number of Ss used. The results for SEXf show that toughmindedness seems to be the key factor for appreciation of sex in jokes, irrespective of the joke's structure. Both components, $\mathrm{C}$ and $\mathrm{T}$, contributed about equally to the location of SEXf; i.e. sex jokes were considered funny by tough, conservative Ss and least funny by tender, liberal Ss. Sex jokes were located in the attitude space with the highest degree of variance explained. But for an exact location the structural basis of sex jokes had to be considered, too. Depending on the loadings on all three factors, we separated INC-RES sex jokes, NON sex jokes and pure sex jokes. Generally speaking, toughmindedness was associated positively with all three groups of sex jokes, but because of their different structure, the jokes were located at different places in the two-dimensional space. NON sex jokes were located directly on the toughmindedness axis, pure sex jokes and INC-RES sex jokes were located on the T/C diagonal, the latter closer to the conservatism axis. Unfortunately, only three sex jokes had a high nonsense loading, therefore the interpretation for NON sex jokes has to be considered with greater caution. All sex jokes correlated positively with the T-factor and nearly all correlations were significant. Also a higher order relationship emerged; the size of the loading of a joke on the sex joke factor depended on its correlation with toughmindedness. In other words, stimulus components (the degree of salience of the (sexual) content, the structure of the joke) and personality components (the individual's position on toughmindedness and conservatism) interact in the judgement of funniness of sex jokes. We have discussed elsewhere (Ruch and Hehl, 1986a) that the toughmindedness hypothesis generally is in line with other hypotheses relating appreciation of sex jokes with hedonism (Wilson, 1973), extraversion or masculinity. 
As far as the rejection component was concerned, sense of humour was located on the tough side; i.e. tender Ss generally gave higher Rejection scores (INC-RESr; NONr and SEXr) to all kinds of jokes. The location of the rejection scales also depended on the structure of these jokes. NONr and NON sexr were located in the conservative/tenderminded quadrant and INC-RESr, INC-RES sexr and PURE sexr were located in the liberal/tenderminded quadrant. In other words, conservatism was responsible for rejection of the structure (liberals rejected jokes based on the INC-RES structure, conservatives rejected jokes based on the nonsense structure) and toughmindedness was responsible for rejection per se (tender ss rejected all kinds of jokes more strongly than tough Ss). In a recent paper (Hehl and Ruch, 1985) we tried to relate the Rejection scores with personality variables. It turned out that SEXf was associated with masculinity, dominance and toughmindedness; low SEXr was associated with Psychoticism, dominance, all sensation seeking scales, venturesomeness, low empathy and spontaneous aggressivity. These are all variables related to toughmindedness and thus support the hypothesis.

\section{A Two Component Model for Appreciation of 'Tendentious' Humour?}

The results suggest, that in sex jokes there are two sources of pleasure: a structure component and a content component. The importance of these two ingredients is different for each of the jokes. The relative contribution of these components can be predicted by $\mathrm{C}$ (for jokes of the INC-RES structure) and by $T$ (the salience of content). If the structure is also important then INC-RES sex jokes should correlate with 'pure' INC-RES jokes highly but not with NON jokes and NON sex jokes should correlate with 'pure' NON jokes highly but not with INC-RES jokes. Indeed, funniness of INC-RES sex jokes correlated very highly with INC-RES jokes $(r=0.69, P<0.001)$ and weakly with NON jokes $(r=0.28, P<0.01)$. Funniness of NON sex jokes correlated highly with NON jokes $(r=0.43, P<0.001)$ but not with INC-RES jokes $(r=0.10, N S)$. Generally speaking, these correlations show that Ss do not respond to the content components of sex jokes exclusively but also (to a higher degree than expected) to structural properties. The content variance suppressed the structure variance in sex jokes. The structure component was linearly related to $C$ but generally lower in size because the total variance of sex jokes was composed of structure as well as content variance.

The question arises, whether there is an additivity of content and structure in appreciation of sex jokes or whether there are interactions. Since the statistical models used in the study can only reveal additive components, we can only speculate about interactions. Nevertheless, there is much evidence that the additive components are dominant. The additive composition of the factor loadings (INC-RES and sex) of the sex jokes is similar to the relative size of the correlations with $\mathrm{C}$ and $\mathrm{T}$. The PHIcoefficients showed that the jokes had nearly identical locations in the two spaces. Thus, at least the position of the jokes in the factor space can be dissected into a content variance and a structure variance and the size of these variances can be predicted very well by coefficients which determine the degree of determinedness of the Funniness ratings of these jokes by conservatism and toughmindedness. An exact estimation of interactive effects will have to be obtained in an experimental design. Using different approaches, Ehrenstein and Ertel (1978) and Wilson (1979) found no significant interactive effects of content and structure upon funniness. 
How large is the proportion of variance of sex jokes attributable to the structure? The range of the loadings of sex jokes on the corresponding structure factor is 0.16 to 0.62 . The sum of the squares of these loadings was 3.19 (the sum of the squares of the loadings on the sex factor was 5.24); indicating that the structure variance accounted for $37.9 \%$ and the content variance accounted for $62.1 \%$ of the explained variance of sex jokes. On the other hand, the content (sex factor) variance in the INC-RES jokes is only about $8.4 \%$ of the explained variance.

Funniness of sex jokes (SEXf) was located closer to the POIR scale than Funniness of INC-RES (INC-RESf) jokes. SEXf is about in the same location as concepts like authoritarianism, Wilson's primary factors 'ethnocentrismintolerance' and 'militarism-punitiveness', need for power, 'law and order'attitude, racialism or dogmatism. Low SEXf can be found where concepts like pacifism, humanitarianism or social interests are located. On the other hand, INC-RESf was located closer to the C Scale than SEXf was. Contrary to expectation (Eysenck and Wilson, 1978, p.136), the C Scale was located on the tender side. This might be due to the German version of the $\mathrm{C}$ Scale. Whether the best location for factors $\mathrm{C}$ and $\mathrm{T}$ was obtained cannot be answered confidently. In any case, the difference that existed between the POIR scale and the $\mathrm{C}$ scale was the same that existed between SEXf and INC-RESf; i.e. the same factors, $T^{\prime}$ and $T^{\prime \prime}$, separated the conservatism scales as well as the humour scales. It is important to note, that only 10 of the 158 attitude items were hedonism or sex items. It is not only this component of $T$ that relates to sex jokes but other components of toughmindedness also contribute. On the contrary, most of the hedonism items correlated (negatively) with the INC-RES factor (but not or only to a lesser extent with SEXf), indicating that tendermindedness might be associated with the content of some jokes of Factor 1. Also Freud (1905) introduced two sources of pleasure in jokes; joke work and the tendency of a joke. But there are two basic differences from his theory. Firstly, he stresses the importance of joke work (structure) in innocent jokes but not in tendentious jokes. Our results show, that the structure is important even in 'tendentious' (sex) jokes. Secondly, he suggests that Ss repressing sexual impulses appreciate sex jokes. There is little evidence to assume that tough Ss repress sexuality; on the contrary, we would expect that this is the case with tenderminded conservative ('antihedonistic') Ss.

Conservatism and the structure of jokes

The question is whether conservatism really can be equated with preference for the structure of jokes. There is some evidence for this view. No joke of the INC-RES structure was preferred by liberals although there were antiliberal contents as well as anti-conservative contents. We never found consistent negative correlations between any pair of jokes within the pool of jokes we have used so far. Therefore it is very unlikely to find jokes (of the INC-RES structure) which are correlated negatively with conservatism; i.e. jokes which are preferred by liberals. Although there were jokes in the first factor that contained stereotypes, and were targeted against minorities, etc. there were also jokes that were purely formal, respectively nonsalient. These jokes also correlated with the C Scale (Ruch, 1984). On the other hand, we showed that regardless of the content of a conservatism item, 
its correlation with the INC-RES jokes rose parallel with its discriminative power (Ruch and Hehl, 1983b).

Although there is little experimental data so far, the correlational studies support Wilson's view that conservatism allows one to predict evaluation of structural properties of stimuli other than jokes (Gillies and Campbell, 1985; Glasgow, Cartier and Wilson, 1985; Wilson, Ausman and Mathews, 1973). 'There is increasing evidence that high C scores reflect an adaptation to intolerance of high levels of stimulus and response uncertainty.' (Wilson, 1985, p. 36) In these studies conservatives tended to prefer simpler (relative to complex) stimuli and liberal ss preferred the more complex stimuli.

Jokes with similar contents (e.g. scatological jokes, sex jokes) but based on the nonsense structure could not be predicted by conservatism. Vice versa, the C-axes were correlated with INC-RES sex jokes but not with NON sex jokes. Generally, appreciation of the second structural factor, Non jokes, is also correlated with variables (higher intelligence, stimulus seeking) which presumably relate to structural properties of stimuli.

The case of disparagement humour

Inclusion of measures of conservatism and toughmindedness might be fruitful in research on disparagement jokes (McGhee and Duffey, 1983; zillmann, 1983). In short, according to the theory, funniness of a joke depends on the identification of the recipient with the person (or group) that is being disparaging and with the victim of the disparagement. The theory proposes that

"...humour appreciation varies inversely with the favourableness of the disposition toward the agent or the entity being disparaged, and varies directly with the favourableness of the disposition toward the agent or the entity disparaging it". Zillmannn and Cantor (1976, pp. 100-101).

Results showed that the model works well in predicting the behaviour of groups which are traditionally superior (e.g. males appreciated jokes in which females were disparaged but showed less appreciation for jokes in which a female disparaged a male) but not of the inferior groups (females showed no preference for 'put down of male'-jokes). On the contrary, sometimes the inferior groups laughed more at jokes putting down a member of their own group. Therefore, the search for moderating variables began (e.g. McGhee and Duffey, 1983). Interestingly, variables were employed which are correlates of toughmindedness and conservatism; e.g. sex role identification, chauvinism, social and income-classes, age or sex. Some disparagement jokes are included in our Factor 1 (but of course in Factor 1 there are also INC-RES jokes that do not disparage any person or group). Suls (1977) demonstrated, that the processing of disparagement jokes is the same as that concerning all other two-stage (incongruity-resolution) jokes. Presumably, disparagement can only take place in the first factor but not in NON jokes. We hypothesize that disparagement jokes can be located in the toughminded/conservative quadrant; i.e. they will be correlated with conservatism and toughmindedness (the size of the latter correlation depends on the degree of the insult). Tough conservatives (e.g. chauvinistic, ethnocentristic, authoritarian) will appreciate disparagement jokes, but tenderminded liberals will not. 
Goldstein, Suls and Anthony (1972) showed, that salience of certain themes leads to increased funniness of jokes of these themes. Probably, the effects predicted by the disparagement theory are moderated by conservatism and toughmindedness. Tendencies like strong preoccupation with power relationships, strengthening in-group ties, feeling superior to the weak, authoritarian aggression, strong separation of in-group and out-group and identification with powerful others are characteristics of the authoritarian personality (Adorno, Frenkel-Brunswik, Levinson and Sanford, 1950). These tendencies imply increased salience of disparagement and thus might lead to greater funniness of put down jokes in tough conservatives. But can we speak of the authoritarian personality as a humorous person? Allport (1954) claims that humour is embedded in another personality background and thus reminds us that there are several (probably antagonistic) aspects of sense of humour.

"...we have grounds for supposing a person's sense of humor is closely related to his degree of self-insight... But we venture to assert that humor is probably an important variable in relation to prejudice. Yet if the syndrome of the prejudiced personality is correctly defined ... we can easily believe that humor is a missing ingredient; also that it is a present ingredient in the syndrome of tolerance. One who can laugh at oneself is unlikely to feel greatly superior to others." Allport (1954, p. 437)

Thus, sense of humour is attributed to tenderminded liberals. But Allport surely did not think of humour in terms of appreciation of disparagement jokes. Nevertheless, the idea that one either can posess sense of humour in terms of the ability to laugh at oneself or in terms of appreciation of (incongruity-resolution) sex jokes and disparagement jokes is indeed fascinating. Explorations in humour still offer more incongruities than resolutions.

R E F E R E N C E S

Adorno T.W., Frenkel-Brunswik E., Levinson D.J. and Sanford R.N. (1950) The Authoritarian Personality. Harper \& Row, New York.

Allport G.W. (1954) The Nature of Prejudice. Addison-Wesley, London.

Allport G.W., Vernon P.E. and Lindzey G. (1960) Study of Values: Manual of Directions. Houghton-Mifflin, New York.

Brengelmann J.C. and Brengelmann L. (1960a) Deutsche Validierung von Fragebogen der Extraversion, neurotischen Tendenz und Rigidität. Z . exp. angew. Psychol. 7, 291-331.

Brengelmann J.C. and Brengelmann L. (1960b) Deutsche Validierung von Fragebogen dogmatischer und intoleranter Haltungen. Z. exp. angew. Psychol. $7,451-471$.

Cloetta B. (1983) Der Fragebogen zur Erfassung von Machiavellismus und Konservatismus MK. Schweiz. Z. Psychol. Anwend. 42, 127-159.

Ehrenstein W.H. and Ertel S. (1978) Zur Genese des Lustigkeitseindrucks. Psychol. Beitr. 20, 360-374. 
Eysenck H.J. (1954) The Psychology of Politics. Routledge \& Kegan Paul, London.

Eysenck H.J. (1976) Sex and Personality. Open Books, London.

Eysenck H.J. and Eysenck M.W. (1985) Personality and Individual Differences. A Natural Science Approach. Plenum Press, London.

Eysenck H.J. and Wilson G.D. (1978) The Psychological Basis of Ideology. University Maryland Press, College Park, Md.

Freud S. (1905) Der Witz und seine Beziehung zum Unbewußten. Deuticke, Wien. Gillies J. and Campbell S. (1985) Conservatism and poetry preference. Br. J. soc. Psychol. 24, 223-227.

Glasgow M.R., Cartier A.M. and Wilson G.D. (1985) Conservatism, sensationseeking and music preferences. Person. individ. Diff. 6, 395-396.

Goldstein J.H., Suls J.M. and Anthony S. (1972) Enjoyment of specific types of humor content: Motivation or salience? In The Psychology of Humor (Edited by Goldstein J.H. and McGhee P.E.). Academic Press, New York.

Hehl F.-J. and Ruch W. (1985) The location of sense of humor within comprehensive personality spaces: an exploratory study. Person. individ. Diff. 6, 703-715.

Kaiser H.F., Hunka S. and Bianchini J.C. (1971) Relating factors between studies based upon different individuals. Multivar. behav. Res. 6, 409-422.

McGhee P.E. and Duffey N.S. (1983) The role of identity of the victim in the development of disparagement humor. J. gen. Psychol. 108, 257-270.

Roth E. (1972) Der Werteinstellungs-Test. Eine Skala zur Messung dominanter Interessen der Persönlichkeit. Handanweisung. Huber, Bern.

Ruch W. (1981) Witzbeurteilung und Persönlichkeit: eine trimodale Analyse. Z . diff. diagn. Psychol. 2, 253-273.

Ruch W. (1984) Konservativismus und Witzbeurteilung: Konvergenz gegenstandsbereichsinterner und -übergreifender Variabilität? Z. diff. diagn. Psychol. 5, 221-245.

Ruch W. and Hehl F.-J. (1983a) Intolerance of ambiguity as a factor in the appreciation of humour. Person. individ. Diff. 4, 443-449.

Ruch W. and Hehl F.-J. (1983b) Gemeinsame Struktur in Witzbeurteilung und Einstellungen? In Bericht uiber den 33. Kongreß der DGfPs in Mainz 1982 (Edited by Lüer G.). Hogrefe, Göttingen. 
Ruch W. and Hehl F.-J. (1985a) Individual differences in sense of humour: do data suggest a new model? Paper presented at the 4 th Int. Congr. on Humour, Cork, Ireland, 26-30 June.

Ruch W. and Hehl F.-J. (1985b) Diagnose des Humors - Humor als Diagnostikum. In Diagnostik psychischer und psychophysiologischer störungen (Edited by Hehl F.-J., Ebel V. and Ruch W.). pp 253-325, DPV, Bonn.

Ruch W. and Hehl F.-J. (1986a) Conservatism as a predictor of responses to humour-I. A comparison of four scales. Person. individ. Diff. 7, 1-14.

Ruch W. and Hehl F.-J. (1986b) Personal values as facilitating and inhibiting factors in the appreciation of humor. Submitted for publication.

Suls J.M. (1972) A two-stage model for the appreciation of jokes and cartoons: An information-processing analysis. In The Psychology of Humor (Edited by Goldstein J.H. and McGhee P.E.). Academic Press, New York.

Suls J.M. (1977) Cognitive and disparagement theories of humor: A theoretical and empirical synthesis. In It's a Funny Thing, Humour (Edited by Chapman A.J. and Foot H.C.). Pergamon Press, Oxford.

Schneewind K.A., Schröder G. and Cattell R.B. (1983) Der 16-PersönlichkeitsFaktoren-Test (16 PF). Huber, Bern.

Schneider J. and Minkmar H. (1972) Deutsche Neukonstruktion einer Konservativismusskala. Diagnostica 18, 37-48.

Terry R.L. and Ertel S.L. (1974) Explorations in individual differences in preferences for humor. Psychol. Rep. 34, 1031-1037.

Wilson Ch.P. (1979) Jokes: Form, Content, Use and Function. European Monographs in Social Psychology, Vol. 16. Academic Press, London.

Wilson G.D. (1973) Conservatism and response to humour. In The Psychology of Conservatism. (Edited by Wilson G.D.). Academic Press, London.

Wilson G.D. (1985) The 'catchphrase' approach to attitude measurement. Person. individ. Diff. 6, 31-37.

Wilson G.D., Ausman J. and Mathews T.R. (1973) Conservatism and art preferences. J. Person. soc. Psychol. 25, 286-289.

Wilson G.D. and Patterson J.R. (1970) The Conservatism Scale. NFER, Windsor, Berks.

Zillmann D. (1983) Disparagement humor. In Handbook of Humor Research, Vol I, Basic Issues. (Edited by McGhee P.E. and Goldstein J.H.). Springer, New York.

Zillmann D. and Cantor J.R. (1976) A disposition theory of humour and mirth. In Humour and Laughter: Theory, Research and Applications (Edited by Chapman A.J. and Foot H.C.). Wiley, London. 
Zuckerman M. (1979) Sensation Seeking: Beyond the Optimal Level of Arousal. Erlbaum, Hillsdale, New Jersey.

Fig. 1 Factor loadings of the 20 marker variables on the two unrotated principal components, conservatism (abscissa) and toughmindedness (ordinate). The humour scales, sex and age are projected into this space using their correlations with the factor scores of the axes as coordinates

Fig. 2 Factor loadings of incongruity-resolution jokes ( ), incongruityresolution sex jokes ( ), nonsense sex jokes ( ) and pure sex jokes ( ) on the incongruity-resolution factor (abscissa) and their correlations with the factor scores of the conservatism axis (ordinate)

Fig. 3 Factor loadings of incongruity-resolution jokes ( ), incongruityresolution sex jokes ( ), nonsense sex jokes ( ) and pure sex jokes () on the sex factor (abscissa) and their correlations with the factor scores of the toughmindedness axis (ordinate)

Table 1. Correlations between the Funniness (columns 1 to 4 ) and Rejection (columns 5 to 8 ) scores of incongruity-resolution, nonsense and sex jokes with the conservatism $\left(C^{\prime}, C^{\prime} '\right)$ and toughmindedness $\left(T^{\prime}, T^{\prime} '\right)$ axes. Sex jokes are also divided into pure sex jokes, incongruity-resolution sex jokes and nonsense sex jokes

Table 2. Correlations of the Funniness scores of single jokes with $C^{\prime}$ and $T^{\prime}$ Table 3. Correlations of the Rejection scores of single jokes with $C^{\prime}$ and $T^{\prime}$ 
Table 1. Correlations between the Funniness (columns 1 - 4) and Rejection (columns 5 - 8) scores of incongruity-resolution, nonsense and sex jokes with the conservatism $\left(C^{\prime}, C^{\prime}{ }^{\prime}\right)$ and toughmindedness $\left(T^{\prime}, T^{\prime}{ }^{\prime}\right)$ axes. Sex jokes are also divided into pure sex jokes, incongruity-resolution sex jokes and nonsense sex jokes

\begin{tabular}{|c|c|c|c|c|c|c|c|c|}
\hline & $C^{\prime}$ & $\begin{array}{c}\mathrm{F} \\
\mathrm{T}^{\prime}\end{array}$ & $n \underset{C^{\prime}}{\sin }{ }^{\prime} s$ & $T^{\prime \prime}$ & $C^{\prime}$ & $R e \underset{T^{\prime}}{j} e$ & 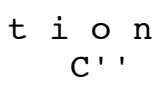 & $T^{\prime \prime}$ \\
\hline $\mathrm{NC}-$ & $0.41 * * *$ & 0.08 & $0.46 * * *$ & 0.06 & $-0.19 *$ & $-0.27 * *$ & $-0.25 * *$ & $-0.25 * *$ \\
\hline D & -0.17 & 0.09 & -0.18 & -0.02 & 0 * & $-0.20 *$ & 0.13 & -0.14 \\
\hline $5 x$ & $.39 * * *$ & $0.37 * * *$ & $0.42 * * *$ & $0.38 * * *$ & -0.05 & $39 * * *$ & -0.15 & $-0.46 * * *$ \\
\hline - pure & $0.40 * * *$ & $0.35 * * *$ & $0.42 * * *$ & $0.38 * * *$ & -0 . & $-0.38 * * *$ & -0.16 & $-0.45 * * *$ \\
\hline $\mathrm{S}$ & $* * *$ & $0.32 * * *$ & $0.47 * * *$ & & & $* * *$ & $-0.22 *$ & $42 * * *$ \\
\hline NON & 0.02 & $0.30 * *$ & 0.05 & $0.28 * *$ & 0.17 & $-0.31 * *$ & 0.10 & $-0.34 * * *$ \\
\hline
\end{tabular}

$* \mathrm{P}<0.05 ; * * \mathrm{P}<0.01 ; * * * \mathrm{P}<0.001$

Table 2. Correlations of the Funniness scores of single jokes with $C^{\prime}$ and $T^{\prime}$

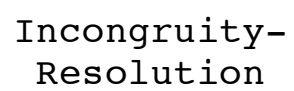

joke

1

2

3

4

5

6

7

8

8

10

11

12

13

14

15

16

17

18

19

20

$\begin{array}{lc}0.38 * * * & 0.27 * * \\ 0.15 & 0.14 \\ 0.10 & -0.08 \\ 0.24 * * & 0.10 \\ 0.19 * & -0.03\end{array}$

$0.19 *-0.03$

$0.02 \quad 0.12$

$0.28 * *-0.03$

$0.37 * * *-0.05$

$0.27 * * 0.23 *$

$0.34 * * *-0.08$

$0.32 * * * 0.03$

$0.24 * * \quad-0.10$

$0.32 * * *-0.01$

$0.29 * * \quad 0.07$

$0.26 * *-0.02$

$0.27 * * 0.07$

$0.17-0.02$

0.19 * 0.21 *

$0.39 * * * 0.17$

\section{Nonsense Jokes}

Sex Jokes

$\begin{array}{llll}C^{\prime} & \mathrm{T}^{\prime} & \mathrm{C}^{\prime} & \mathrm{T}^{\prime}\end{array}$

$\begin{array}{lr}-0.05 & 0.01 \\ -0.19 * & 0.12 \\ -0.10 & -0.00 \\ 0.02 & 0.04 \\ -0.22 * & 0.08 \\ -0.15 & 0.17 \\ -0.05 & 0.06 \\ -0.16 & -0.01 \\ -0.11 & 0.20 \\ -0.17 & -0.01 \\ 0.03 & 0.06 \\ -0.28 * * & 0.06 \\ -0.08 & 0.09 \\ -0.10 & -0.04 \\ -0.18 * & -0.01 \\ -0.07 & 0.12 \\ 0.02 & -0.02 \\ -0.14 & -0.06 \\ 0.05 & -0.04 \\ 0.02 & 0.16\end{array}$

$\begin{array}{ll}0.29 * * & 0.30 * * \\ 0.37 * * * & 0.17 \\ 0.32 * * * & 0.23 * \\ 0.32 * * * & 0.19 * \\ 0.35 * * * & 0.21 * \\ 0.19 * & 0.22 * \\ -0.06 & 0.24 * * \\ -0.10 & 0.08 \\ 0.22 * & 0.33 * * * \\ 0.32 * * * & 0.28 * * \\ 0.19 * & 0.26 * * \\ 0.15 & 0.24 * \\ 0.33 * * * & 0.34 * * * \\ 0.12 & 0.08 \\ 0.30 * * & 0.35 * * * \\ 0.08 & 0.20 * \\ 0.38 * * * & 0.14 \\ 0.53 * * * & 0.28 * * \\ 0.20 * & 0.15 \\ 0.45 * * * & 0.29 * *\end{array}$


Table 3. Correlations of the Rejection scores of single jokes with $C^{\prime}$ and $T^{\prime}$

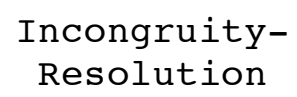

joke

$\begin{array}{rllll}1 & -0.21 * & -0.29 * * & 0.13 & 0.01 \\ 2 & -0.08 & -0.10 & 0.19 * & -0.15 \\ 3 & -0.05 & -0.04 & 0.14 & -0.06 \\ 4 & -0.14 & -0.30 * * & 0.00 & -0.15 \\ 5 & -0.08 & -0.07 & 0.27 * * & -0.11 \\ 6 & -0.11 & 0.02 & 0.13 & -0.26 * * \\ 7 & 0.14 & -0.29 * * & 0.03 & -0.18 \\ 8 & -0.04 & -0.09 & 0.23 * & -0.16 \\ 9 & -0.01 & -0.22 * & 0.09 & -0.25 * * \\ 10 & -0.03 & -0.16 & 0.00 & -0.16 \\ 11 & -0.15 & -0.07 & -0.01 & -0.09 \\ 12 & -0.23 * & -0.11 & 0.04 & -0.10 \\ 13 & -0.13 & -0.01 & 0.14 & -0.09 \\ 14 & -0.23 * & -0.08 & 0.17 & 0.08 \\ 15 & -0.04 & -0.24 * * & 0.31 * * & -0.10 \\ 16 & -0.03 & -0.08 & 0.04 & -0.14 \\ 17 & -0.28 * * & -0.12 & 0.13 & -0.04 \\ 18 & 0.08 & -0.05 & -0.01 & -0.00 \\ 19 & 0.08 & -0.32 * * * & -0.04 & -0.02 \\ 20 & -0.34 * * * & -0.23 * & 0.05 & 0.06\end{array}$

* $\mathrm{P}<0.05 ; * * \mathrm{P}<0.01 ; * * * \mathrm{P}<0.001$
Sex Jokes

$C^{\prime} \quad T^{\prime}$

$\begin{array}{ll}-0.24 * * & -0.17 \\ -0.11 & -0.27 * * \\ 0.00 & -0.35 * * * \\ -0.04 & -0.25 * * \\ -0.17 & -0.34 * * * \\ 0.02 & -0.29 * * \\ 0.16 & -0.24 * * \\ 0.18 * & -0.17 \\ 0.07 & -0.30 * * \\ -0.15 & -0.17 \\ -0.07 & -0.27 * * \\ 0.13 & -0.24 * * \\ -0.08 & -0.36 * * * \\ 0.07 & -0.23 * \\ -0.21 * & -0.33 * * * \\ 0.21 * & -0.36 * * * \\ -0.20 * & -0.18 \\ -0.19 * & -0.40 * * * \\ 0.07 & -0.22 * \\ -0.20 * & -0.34 * * *\end{array}$




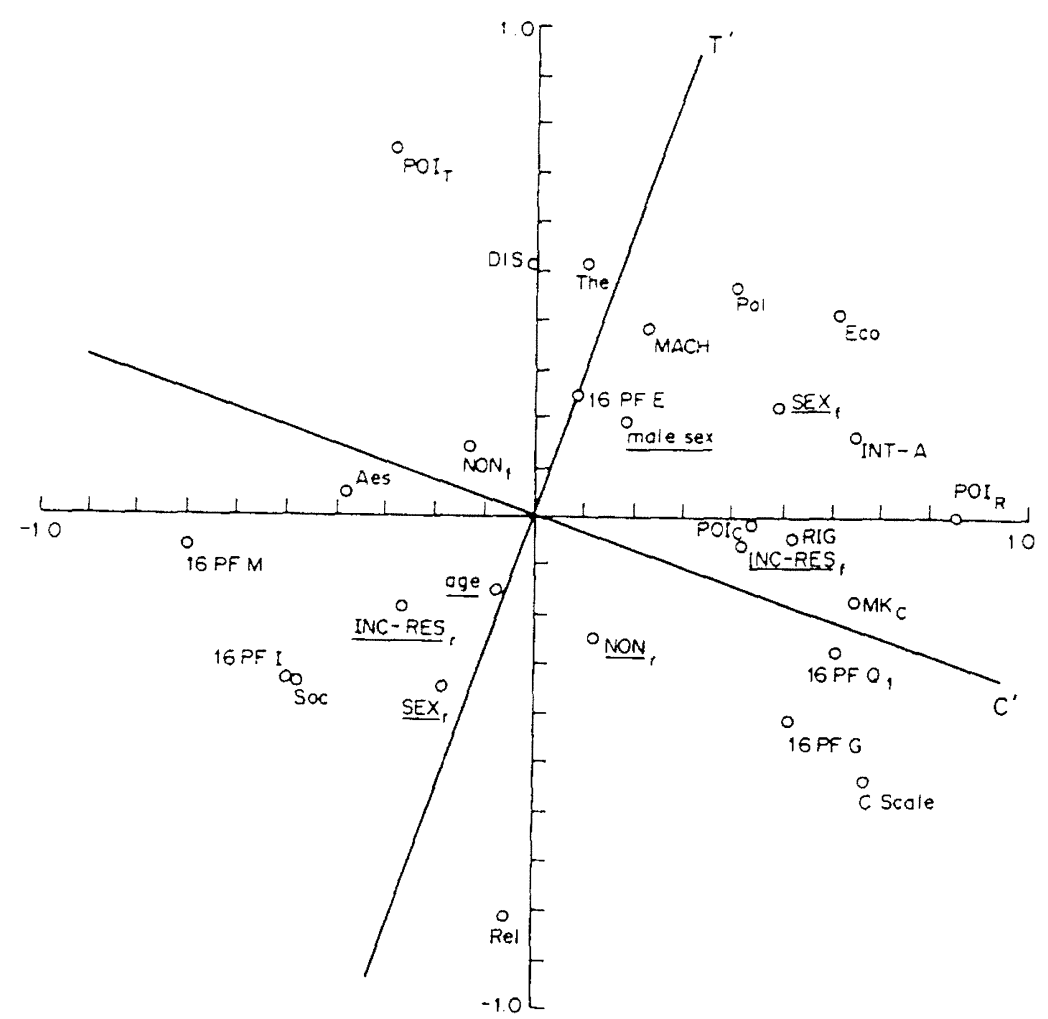

Fig. 1. Factor loadings of the 20 marker variables on the two unrotated principal components, conservatism (abscissa) and toughmindedness (ordinate). The humour scales, sex and age are projected into this space using their correlations with the factor scores of the axes as coordinates.

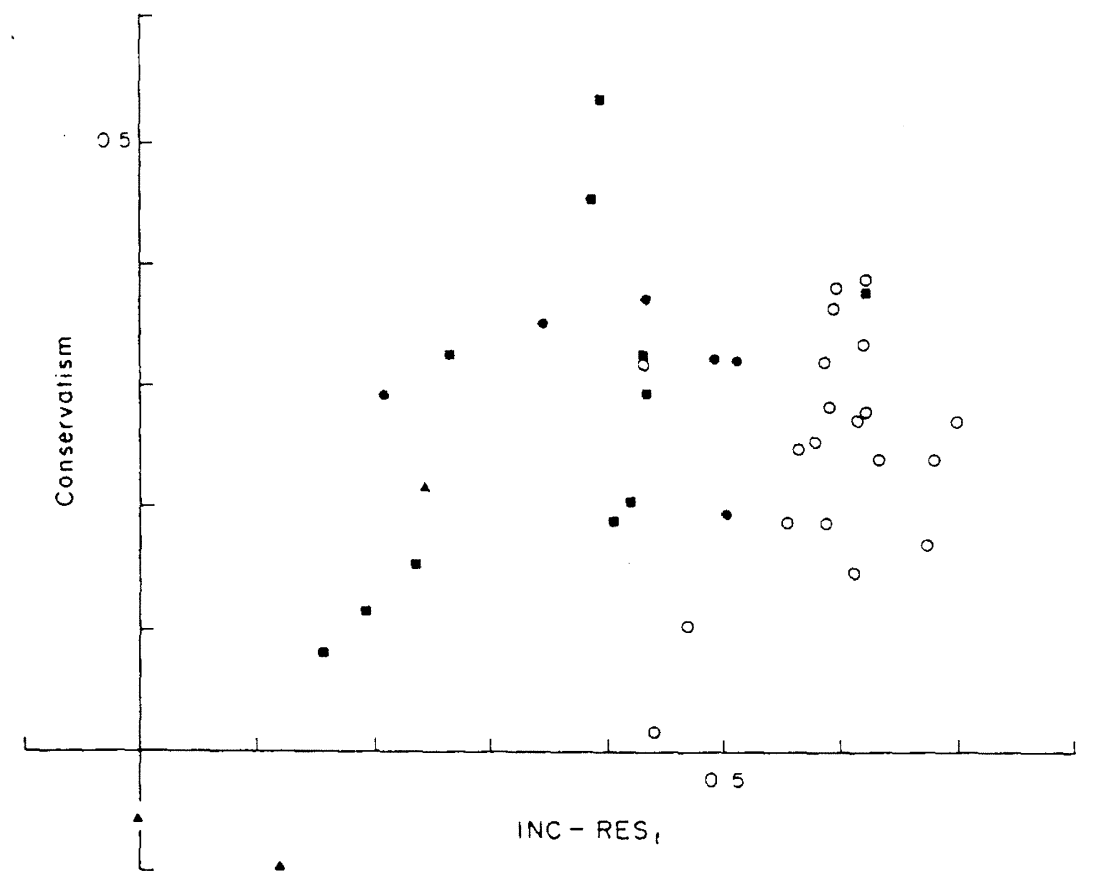

Fig. 2. Factor loadings of incongruity-resolution jokes $(O)$, incongruity-resolution sex jokes nonsense sex jokes $(\boldsymbol{\Lambda})$ and pure sex jokes $(\boldsymbol{\square})$ on the incongruity-resolution factor (abscissa) and their correlations with the factor scores of the conservatism axis (ordinate). 


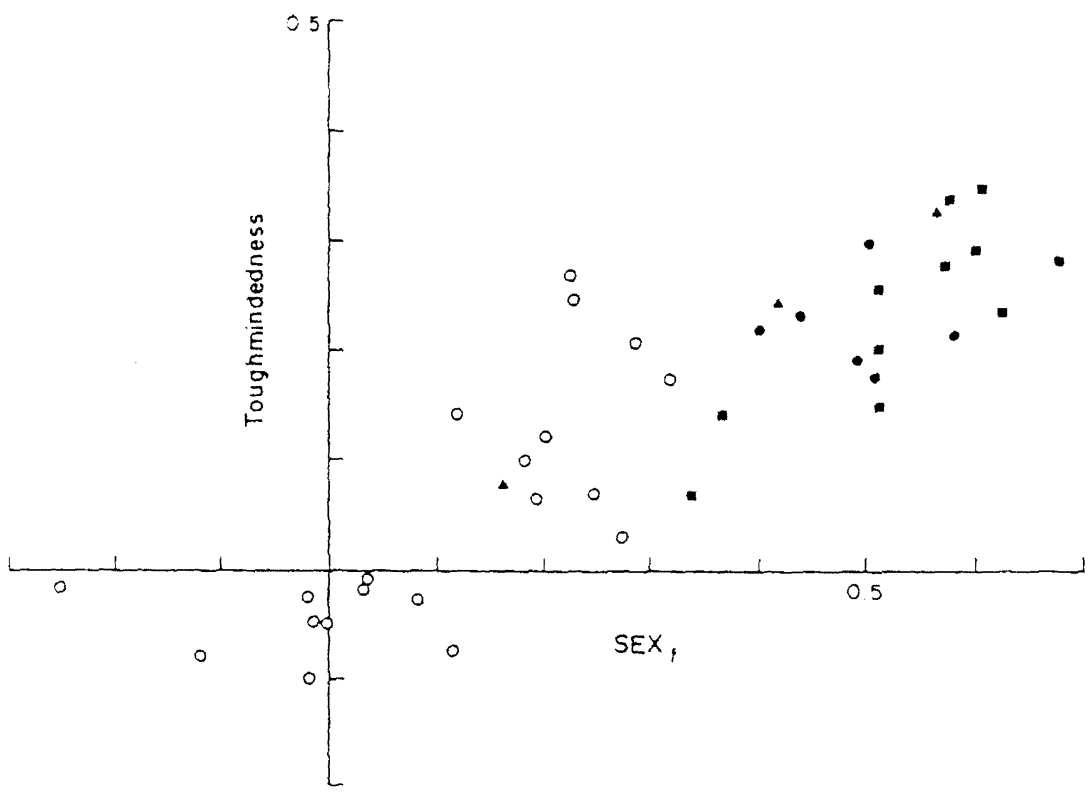

Fig. 3. Factor loadings of incongruity-resolution jokes $(0)$, incongruity-resolution sex jokes (-) nonsense sex jokes ( $\mathbf{\Lambda}$ ) and pure sex jokes ( $\mathbf{(}$ ) on the sex factor (abscissa) and their correlations with the factor scores of the toughmindedness axis (ordinate). 